\title{
Correction to: Fatigue assessment of the welded joints containing process relevant imperfections
}

\author{
Ehsan Javaheri ${ }^{1} \cdot$ Kimiya Hemmesi $^{2} \cdot$ Peter Tempel $^{1} \cdot$ René Fenzl $^{3} \cdot$ Majid Farajian $^{1}$ \\ (C) International Institute of Welding 2019
}

Correction to: Welding in the World (2019) 63:249-261

https://doi.org/10.1007/s40194-018-00676-y

In the original version of this article the author René Fenzl is missing due to an oversight.

The correct author list is as given in this correction.

Publisher's note Springer Nature remains neutral with regard to jurisdictional claims in published maps and institutional affiliations.

The online version of the original article can be found at https://doi.org/ 10.1007/s40194-018-00676-y

Majid Farajian

majid.farajian@iwm.fraunhofer.de

1 Fraunhofer Institute for Mechanics of Materials IWM, Freiburg, Germany

2 Institute of Computational Material Science, IAM CMS, KIT, Karlsruhe, Germany

3 SLV Halle GmbH, Halle, Germany 